\title{
An investigative study on application of carbon nanotubes for strain sensing
}

\author{
M. R. Khodke ${ }^{1}$, Satishchandra V. Joshi ${ }^{2}$ \\ ${ }^{1}$ Mechanical Engineering Department, Vishwakarma Institute of Technology Pune-411037, \\ Maharashtra, India \\ ${ }^{2}$ Principal, Padmabhushan Vasantraodada Patil Institute of Technology, Budhgaon-416304, \\ Sangli, Maharashtra, India \\ moreshwar.khodke@vit.edu, joshisv17@gmail.com
}

PACS 61.48.De; 07.10.Pz; 73.50.Dn

DOI 10.17586/2220-8054-2016-7-4-755-758

Traditional strain sensors, such as metal foil gauges, can measure the strains only on the structural surface in designated directions and locations. Hence, there is a need to develop new types of strain sensors which can function on both the micro-and macro-scale, either on the surface or embedded in the structure, and able to behave as multifunctional materials. Owing to its outstanding electrical and mechanical properties carbon nanotubes (CNTs) can be used as strain sensing material. A film (Bucky paper/CNT network) made from multiwalled carbon nanotubes by use of solvent/surfactant and vacuum filtration method is used as strain sensor.

The paper discusses the experimental work involving preparation of CNT film sensor specimen, its application on aluminum and brass strips along with conventional foil gauge and subjecting the metal strips to axial loading to measure gauge factor. It was found that CNT film strain sensor shows linear relationship between change in resistance and strain. Furthermore, the gauge factor increases as the film aspect ratio increases, and for the same aspect ratio, a higher gauge factor was observed for brass than aluminum.

Keywords: carbon nanotube, strain sensor, bucky paper, sensitivity, gauge factor.

Received: 22 March 2016

\section{Introduction}

Mechanical strain sensors are widely used for structural health monitoring and vibration control. Traditional strain sensors such as strain gauges are sensitive, stable, of low cost and easy to use. However, strain gauges can only measure the strains on the structural surface in designated directions and locations; also strain sensing is usually the only function they can offer. Carbon nanotubes (CNTs) possess excellent physical and chemical properties [1] and strain sensor made of carbon nanotube material can alleviate this difficulty and can behave as multifunctional material.

Comprehensive reviews on sensors based on carbon nanotubes and their composites are presented by Christofer Hierold et al. [2] and Chunyu Li et al. [3]. A study by Dharap et al. [4] showed that pure SWCNT films ('bulky paper') can serve as strain sensors if they are bonded to the structural surface as conventional strain sensors.

Strain sensitivity is one of the most important parameters to consider and is expressed as the gauge factor (GF), a dimensionless number describing the change in resistance as a ratio of applied strain, and is given by [5]:

$$
G F=\frac{\text { Relative change in resistance }}{\text { Applied strain }}=\frac{(\Delta R / R)}{\varepsilon} .
$$

The effect of aspect ratio on sensitivity of CNT film sensor is not reported in the literature. The investigation of this relationship is the objective of this study.

\section{Carbon nanotube film}

Many applications of CNT film are reported in the literature [6]. Some of them are in field emission, energy storage and conversion, electronics, humidity and temperature sensor, gas sensors, bio sensor etc. The methods for preparation of CNT film are chemical vapor deposition growth, electrophoretic deposition, drop drying from solvent etc. Vacuum filtration method as outlined in [7] is used in this study. 


\subsection{Preparation of CNT Film}

Multiwalled carbon nanotubes (MWCNTs) having an average inner and outer diameters 4-13 nm, and length of 1-4 $\mu \mathrm{m}$ was procured from D \& D Advanced Materials, Pune, India. $25 \mathrm{mg}$ of MWCNT, as procured, was mixed in $100 \mathrm{ml}$ of Dimethylformamide (DMF) solvent. DMF-MWCNT solution was then ultrasonicated in a bath sonicator (DC-80H, MRC, $80 \mathrm{~W}$ ) for 3 hours and by an ultrasonic tip (Vibra-Cell VCX130, Sonics, USA) for $20 \mathrm{~min}$ in an alternating sequence. CNT suspension was then filtered by using vacuum filtration method. The film is peeled off from filter paper and dried in oven at 60 to $80{ }^{\circ} \mathrm{C}$ for 12 hours. The film after drying is cut in required aspect ratios and used as strain sensor.

\section{Experimental setup}

The setup consists of Universal Testing Machine (UTM) for tensile loading (1-10 kN) of specimens and Agilent 34410A digital multimeter for measuring the resistance change. The CNT film strain sensors and conventional metal foil strain gauge are bonded on opposite side of on aluminum or brass strip by epoxy adhesive. The terminals for the electrical resistance measurements were taken from film through silver paste.

Four sensors of different aspect ratio as mentioned in Table 1, were used on Aan aluminum strip of size $300 \mathrm{~mm} \times 30 \mathrm{~mm} \times 3 \mathrm{~mm}$ and on a Brass strip of size $300 \mathrm{~mm} \times 50 \mathrm{~mm} \times 6 \mathrm{~mm}$.

TABLE 1. Specifications of CNT Film and metal foil strain sensors

\begin{tabular}{|c|c|c|c|c|}
\hline Sensor Type & CNT Film Size & $\begin{array}{c}\text { Aspect } \\
\text { Ratio }\end{array}$ & Used on & $\begin{array}{c}\text { Initial Resistance, } \\
\mathbf{R}_{0}, \mathbf{O h m}\end{array}$ \\
\hline Sensor 1 & $30 \mathrm{~mm} \times 10 \mathrm{~mm}$ & $3: 1$ & Aluminium Strip & 19.0365 \\
\hline Sensor 2 & $20 \mathrm{~mm} \times 10 \mathrm{~mm}$ & $2: 1$ & Aluminium Strip & 11.2752 \\
\hline Sensor 3 & $10 \mathrm{~mm} \times 10 \mathrm{~mm}$ & $1: 1$ & Aluminium Strip & 5.0815 \\
\hline Sensor 4 & $30 \mathrm{~mm} \times 10 \mathrm{~mm}$ & $3: 1$ & Brass Strip & 42.1362 \\
\hline Metal Foil 1 & & & Aluminium Strip & 349.565 \\
\hline Metal Foil 2 & & & Brass Strip & 350.005 \\
\hline
\end{tabular}

\section{Results and discussion}

The relative change in resistance with respect to applied strain for three CNT film sensors, Sensor 1 to 3 and conventional metal foil gauge applied on aluminum strip is shown in Fig. 1.

The relative change in resistance with respect to applied strain for sensor 4 and one conventional metal foil gauge applied on brass strip is shown in Fig. 2.

Gauge factor is slope of straight line fitted in the graphs shown in Fig. 1 and Fig. 2. The gauge factors were determined for all these six sensors using equation (1) i.e. slope of straight lines fitted are listed in Table 2.

TABLE 2. Gauge factors for CNT sensors of different aspect ratio

\begin{tabular}{|c|c|c|c|c|c|}
\hline Sensor Type & Film Size & $\begin{array}{c}\text { Aspect } \\
\text { Ratio }\end{array}$ & Used on & $\begin{array}{c}\text { Initial Resistance, } \\
\mathbf{R}_{0}, \mathbf{O h m}\end{array}$ & $\begin{array}{c}\text { Gauge Factor } \\
\text { observed }\end{array}$ \\
\hline Sensor 1 & $30 \mathrm{~mm} \times 10 \mathrm{~mm}$ & $3: 1$ & Aluminium & 19.0365 & 1.05 \\
\hline Sensor 2 & $20 \mathrm{~mm} \times 10 \mathrm{~mm}$ & $2: 1$ & Aluminium & 11.2752 & 0.59 \\
\hline Sensor 3 & $10 \mathrm{~mm} \times 10 \mathrm{~mm}$ & $1: 1$ & Aluminium & 5.0815 & 0.38 \\
\hline Sensor 4 & $30 \mathrm{~mm} \times 10 \mathrm{~mm}$ & $3: 1$ & Brass & 42.1362 & 1.38 \\
\hline Metal Foil 1 & & & Aluminium & 349.565 & 2.10 \\
\hline Metal Foil 2 & & & Brass & 350.005 & 1.99 \\
\hline
\end{tabular}

Gauge factor for metal foil strain gauge as supplied by the manufacturer is 2.0 , which validates the observations shown in Table 2. 


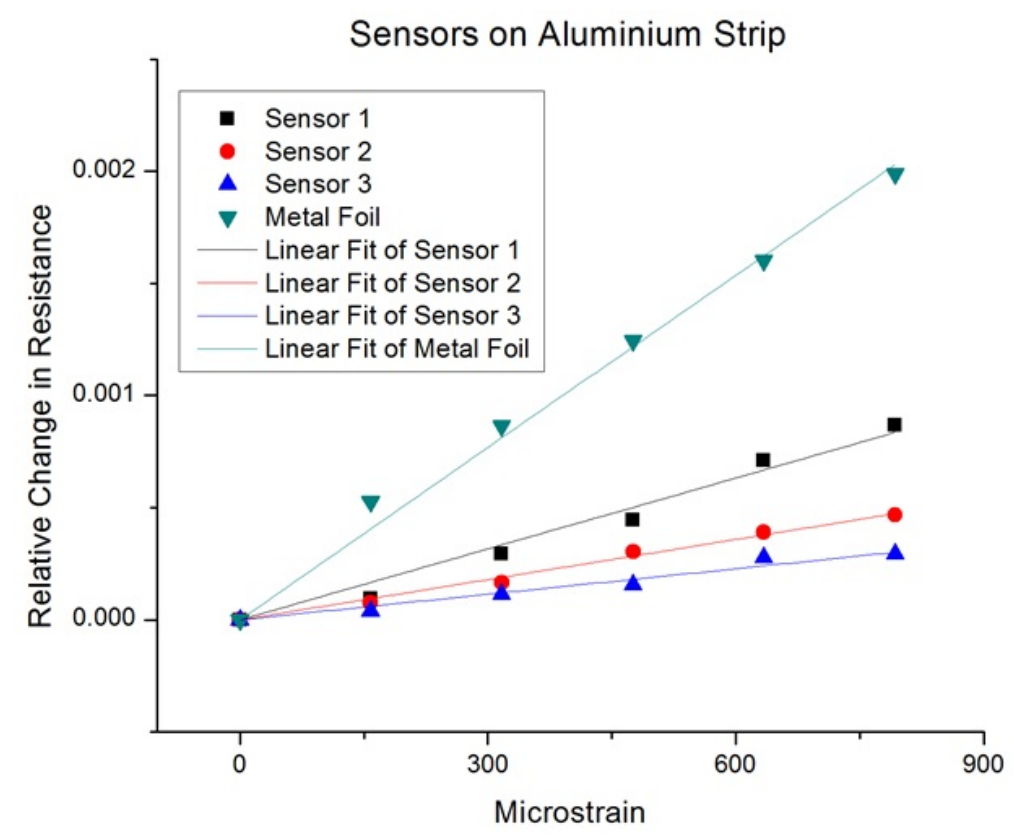

FIG. 1. Relative resistance change vs applied strain for sensors on Aluminium strip

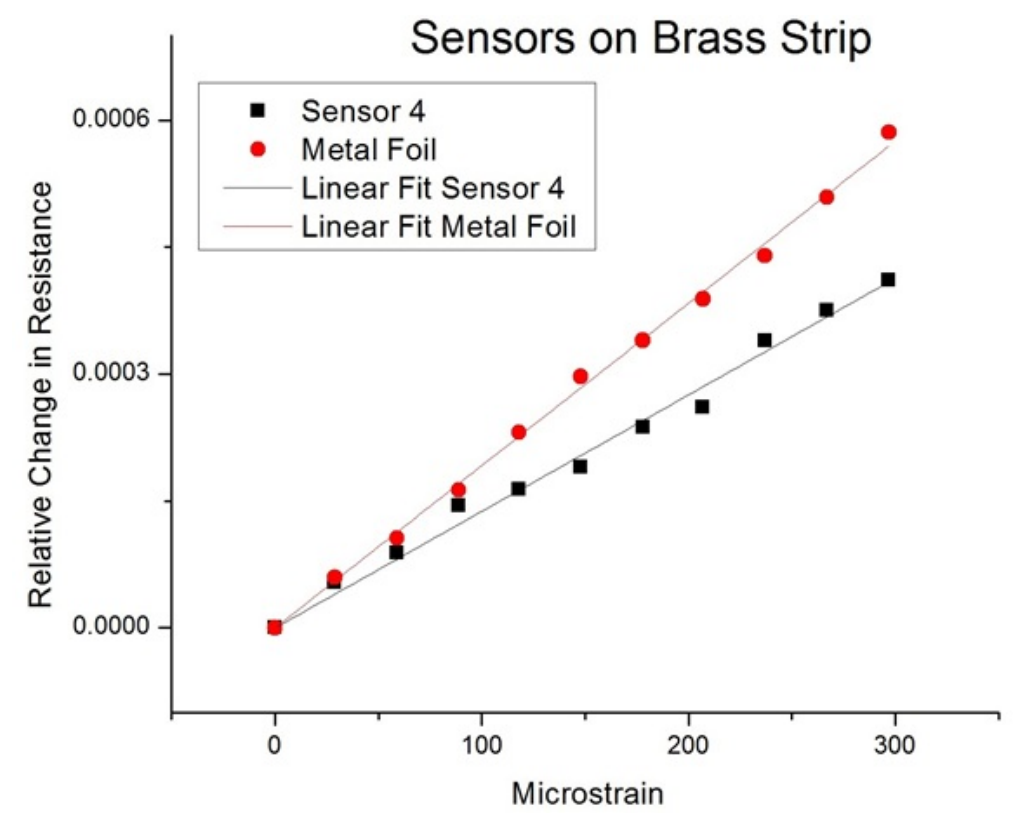

FIG. 2. Relative resistance change vs applied strain for sensors on Brass strip

\section{Conclusion and future scope}

CNT film sensors show nearly linear response to applied strain similar to conventional metal foil gauges. Sensitivity of CNT film sensor is affected by aspect ratio. Higher aspect ratios were shown to result in better sensitivity. Additionally, a higher gauge factor noted for CNT sensor mounted brass strip than that mounted on an aluminum one, suggesting its better suitability for brass material. 


\subsection{Future scope}

The following two points can be suggested as future scope of study:

(1) Magnitude of resistance change for a CNT film is proportional to its initial resistance which in turn depends on its thickness. Hence, resistance change and sensitivity of sensor can be increased by reducing film thickness i.e. by lowering CNT content in film.

(2) Alternatively, initial resistance of CNT film can also be increased by manufacturing composite film of CNT with polymers, e.g., Poly Dimethyl Siloxane (PDMS).

\section{Acknowledgement}

Authors gratefully acknowledge the Research Grant No. 13ENG001061 received from the Board of College and University Development (BCUD), Savitribai Phule Pune University, Pune, India, for the research work.

\section{References}

[1] Dresselhaus M.S., Dresselhaus G., Charlier J.C., Hernandez E., Electronic, thermal and mechanical properties of carbon nanotubes. Philos. Trans. R. Soc. A Math. Phys. Eng. Sci., 2004, 362(1823), P. 2065-2098.

[2] Hierold C., Jungen A., Stampfer C., Helbling T. Nano electromechanical sensors based on carbon nanotubes. Sensors Actuators A Phys., 2007, 136(1), P. 51-61.

[3] Li C., Thostenson E.T., Chou T.-W. Sensors and actuators based on carbon nanotubes and their composites: A review. Compos. Sci. Technol., 2008, 68(6), P. 1227-1249.

[4] Dharap P., Li Z., Nagarajaiah S., Barrera E.V. Nanotube film based on single-wall carbon nanotubes for strain sensing. Nanotechnology, 2004, 15(3), P. 379-382.

[5] Stephan B., Graham E., Michael K., Neil W. MEMS Mechanical Sensors. Artech House, Boston, 2004,86 p.

[6] Zhu H., Wei B. Assembly and applications of carbon nanotube thin films. J. Mater. Sci. \& Technol., 2008, 24(4), P. 447-456.

[7] Rein M.D., Breuer O., Wagner H.D. Sensors and sensitivity: Carbon nanotube buckypaper films as strain sensing devices. Compos. Sci. Technol., 2011, 71(3), P. 373-381. 